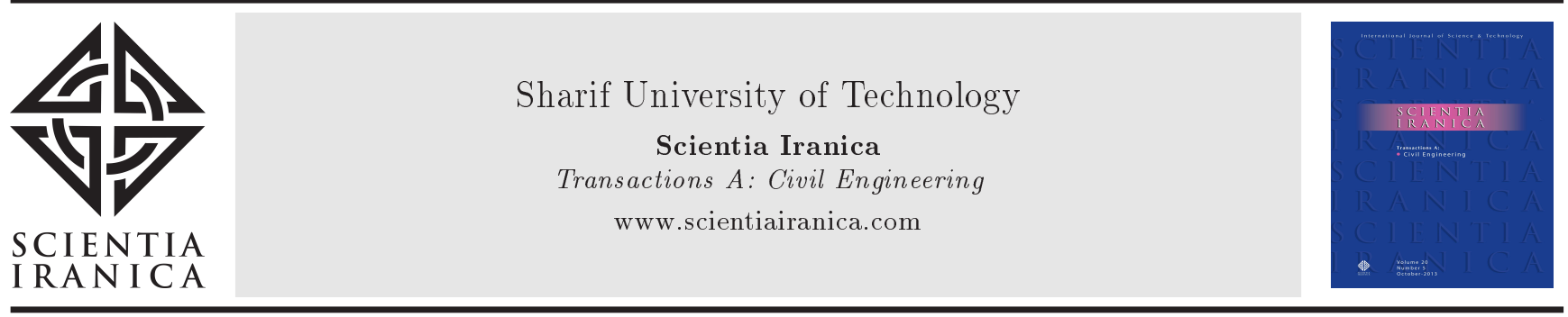

\title{
Evaluation of sensitivity of CBFs for types of bracing and story numbers
}

\author{
A. Asghari* and B. Azimi \\ Faculty of Civil Engineering, Urmia University of Technology, Urmia, P. O. Box 57155-419, Iran.
}

Received 20 October 2014; received in revised form 11 October 2015; accepted 26 December 2015

\author{
KEYWORDS \\ Ductility reduction \\ factor; \\ Response modification \\ factor; \\ Steel concentrically \\ braced frames; \\ Double large-scale \\ concentrically brace; \\ Pushover analysis; \\ Target displacement.
}

\begin{abstract}
Recently, there have been many studies about ductility reduction factor of CBFs, because AISC's seismic design provision has been changed significantly since 2010 . Therefore, a comprehensive study is needed for seismic designing and ductility reduction factor of CBFs. In this study, about 160 two-dimensional CBFs with different types of bracing are designed according to AISC-341, and ductility reduction factor of designed frames is compared to types and formation of bracings in the height of frames. The results confirm that ductility reduction factor and response modification factor of CBFs are mostly dependent on types and formation of bracing. Also, maximum allowable height of OCBFs can be reduced for some types of bracing and be increased for some other types of bracings. For SCBFs, ductility reduction factor depends on the bracing type and number of frame stories. For most of SCBFs, ductility reduction factor cannot achieve more than ten-story frames. So, for these kinds of frames, maximum allowable height should be decreased, or smaller response modification factor should be used. For double large-scale CBFs, because of the enormous stiffness of one-to-seven-story frames, ductility reduction factor cannot be obtained and a smaller response modification factor should be used.
\end{abstract}

(C) 2017 Sharif University of Technology. All rights reserved.

\section{Introduction}

In most of codes of practice for earthquake resisting design, structures are allowed to go beyond the elastic limits in severe earthquakes. So, structures can dissipate most of the earthquake's energy throughout deflection and entering into an inelastic phase of response of structures [1-4].

When structures enter into inelastic phase, seismic forces depend on the deflections which a structure can experience. In most of earthquake resisting design codes, considering the effect of inelastic deformations on the response of structures, the seismic force can be reduced using a reduction factor, termed as response

*. Corresponding author. Tel./Fax:: +982122098346 E-mail addresses: a.asghari@uut.ac.ir (A. Asghari); behnam.azimi@civil.uut.ac.ir (B.Azimi) modification factor, $\mathrm{R}$. The role of the response modification factor is essential in designing the earthquake load-resisting elements. The response modification factors, firstly proposed by the ATC-3-06 report [5], were in fact selected through committee consensus based on the performance of buildings during past earthquakes and on the estimates of system ductility, overstrength, redundancy, etc. [6].

Although designing structures, using seismic force reduction factor, is a simple procedure, but practical engineers always worry about structure's response modification factor. To investigate the accuracy of the method, lots of efforts have been made by researchers.

Ordinary concentrically braced frames are one of the most popular structural systems among structural designers, because of high stiffness and a simple and cost-effective construction.

Also, most of the famous designing codes, such 
as ASCE7 [7] and AISC-341 [8], paid special attention to OCBFs. besides, there have been lots of studies about buckling of bracing members and the system's overstrength and ductility reduction factor of OCBFs $[9,10]$. Uang and Nakashima [11] proved in their studies that using unbuckable bracing members can improve the hysteretic response of OCBFs and also increase the ductility of the system. AISC-341 design code categorizes concentrically-braced frames into two categories: Ordinary Concentrically Braced Frames (OCBFs) and Special Concentrically Braced Frames (SCBFs). Also, it tried to cover up the imperfection of bracing members buckling by limiting width to thickness ratio of braced members' section and proposing obligation for limiting slenderness ratio of bracing members.

There are many numerical and experimental studies [12-18] about overstrength factor and ductility reduction factor of OCBFs. Balendra and Huang [19] found out that the overstrength factor, ductility reduction factors of X-bracing system, and inverted $\mathrm{V}$ bracing system are almost the same. Also, results confirmed that ductility reduction factor of concentrically braced frames decreases as the height of the frames increases. Jinkoo Kim and Hyunhoon Choi [20] showed in their studies that response modification factor of inverted V-braced frames is usually smaller than the values specified in design codes.

According to experimental and analytical studies, building design codes try to cover up CBFs imperfections. For example, AISC-341-2010 has proposed some extra provisions for specially concentrically braced frames in comparison with the AISC-341-2005. According to AISC-2010, columns and beams of SCBFs should be designed according to the analysis in which all of the bracing members reach their maximum capacity. So, according to the newest code, it is expected that nonlinear behavior of concentrically braced frames improves, and their ductility reduction factor increases.

Because most of available analytical and experimental studies are in accordance with AISC-2005 and previous versions of AISC design code, This paper tries to evaluate linear and nonlinear behaviors of CBFs which are designed according to newly-edited AISC2010. The main goal of this paper is to study if CBFs, designed according to AISC-2010, can attain the expected ductility or not. Also, in this paper, sensitivity of ductility reduction factor of frames to types of bracing and number of bracing stories is evaluated.

\section{Supplementary seismic provisions for concentrically braced moment frames}

The AISC-341-10 design code has categorized concentrically braced frame into two categories: ordinary and special concentrically braced frames. Moreover, it introduced separate seismic provisions for each frame. The most important seismic provisions for concentrically braced frames are as follows:

a) Ordinary Concentrically Braced Frames (OCBFs). According to AISC-341-10, for designing beams, columns, and bracing sections of ordinary concentrically braced frames with X-bracing, no supplementary seismic provision is needed. But, for ordinary concentrically braced frames with inverted V-bracing system (chevron bracing), the following provisions should be taken into consideration:

1) Beams of braced bays should have enough capacity for vertical forces of gravity load combinations without considering bracing;

2) Beams of braced bays and their connections to the columns should have enough capacity for unbalanced seismic loads which are combined with factored gravity loads.

When analyzing the beam's static equilibrium, the force of compression resisting brace should be considered as equal to $0.3 P_{n}$, and tension resisting brace's force should be taken as the minimum of $R_{y} F_{y} A_{g}$. In addition, the tension results from amplified seismic load combinations.

b) Special Concentrically Brace Frames (SCBFs). For special concentrically braced frames, the required strength of beams and columns should not be less than the results of the following analyses:

1) Analysis in which tension and compression forces in bracing members are assumed to be $R_{y} F_{y} A_{g}$ and $1.14 F_{c r e} A_{g}$, respectively;

2) Analysis in which tension and compression forces in bracing members are assumed to be $R_{y} F_{y} A_{g}$ and $0.3^{*} 1.14 * F_{\text {cre }} A_{g}$, respectively.

\section{Frames' specifications used in this study}

In this paper, for evaluating elastic and inelastic responses of ordinary concentrically braced frames, a new bracing formation is introduced: double largescale concentrically bracing formation. Also, ten series of braced frames from one to sixteen stories are modeled, totally 160 frames, out of which 5 series of the selected frames are braced using the ordinary bracing system; the other 5 series are braced using the special concentrically bracing system. Each part of five series is defined as follows (Figure 1):

CBF-1 X-Shape concentrically braced frames that are adjacent in the two middle bays; 


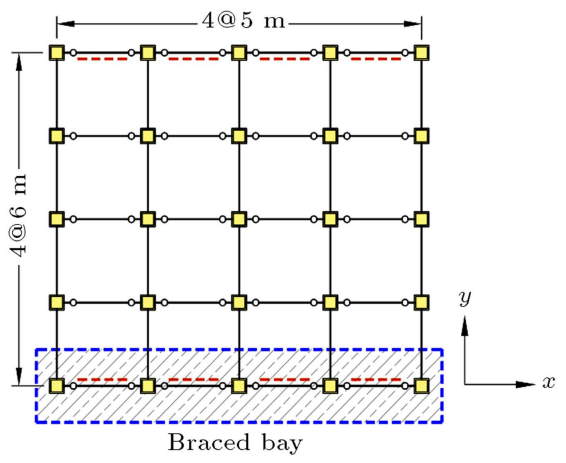

(a) Plan view

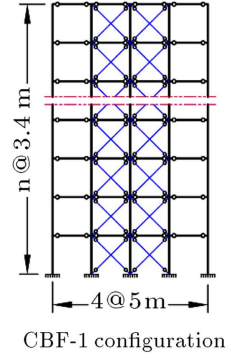

CBF-1 configuration

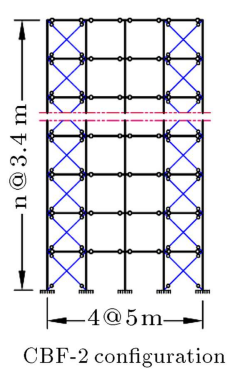

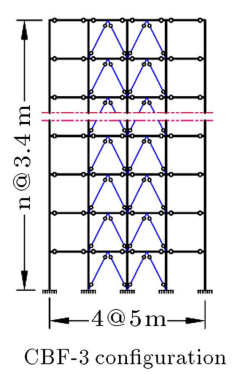

(b) Elevation view
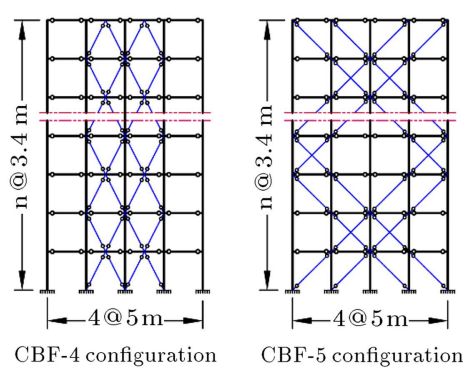

Figure 1. Five types of concentrically braced frames.

CBF-2 X-Shape concentrically braced frames that are braced in the two separate bays;

CBF-3 Inverted V-shape concentrically braced frames;

CBF-4 Combined inverted V-shape and V-shape concentrically braced frames;

CBF-5 Double large-scale concentrically braced frames.

Assumptions used for analysis and design of the frames are as follows:

- 4 frames are used with bay length of $5 \mathrm{~m}$ and story height of $3.4 \mathrm{~m}$, Dead and Live loads which are applied to the beams are $28 \mathrm{kN} / \mathrm{m}$ and $6 \mathrm{kN} / \mathrm{m}$, respectively;

- Seismic loading is applied according to ASCE710 and an equivalent static procedure is used for estimating seismic design force [21];

- According to the Iranian code of practice for seismic resistant design of buildings, response modification factor for SCBFs is assumed to be 5.5; it is assumed to be 3.5 for OCBFs;

- It is assumed that frames are located in a high seismic zone area with peak ground acceleration factor of $0.35 \mathrm{~g}$. Buildings are assumed to be located on the soil type 2 and with moderate level of occupancy;

- It is assumed that frames are a part of the seismic force resisting system of 3D buildings and seismic weights of the frames are 4 times the dead and live loads, which are applied to them;

- ETABS2000 software is used for analyzing and designing steel frames and also according to AISC341 , LRFD method is used for designing steel frames $[22,23]$;

- Used material is assumed to be ST37 with a module of elasticity of $2 \times 10^{5} \mathrm{MPa}$ and yield stress of 240 $\mathrm{MPa}$;

- Used sections of frame members are according to Table 1, it should be noted that the variety of used beam sections are only for seismic design considerations rather than gravity load- bearing needs.

By seismic provisions of AISC-340-10, All of 160 frames with special and ordinary concentrically bracing systems with response modification factors of 3.25 and 5.5 , respectively, are designed in a way that the ratio of required strength to design strength of all members is less or equal to one. For applying a supplementary seismic provision, explained in Section 2 of this paper, the frames should be designed according to appropriate design code. And, first, bracings should be omitted from the model. To avoid the instability of the system, structures floors should be restricted against lateral displacement. Then, seismic design forces should be applied; frames should be analyzed and designed with factored gravity loads.

Considering all of seismic provisions for 160 frames is a time-consuming and conflicting procedure; therefore, for applying seismic design provisions, tem- 
Table 1. Used sections for columns, bracings and beams.

\begin{tabular}{|c|c|c|c|c|c|}
\hline \multicolumn{2}{|c|}{ Column sections } & \multicolumn{2}{|c|}{ Bracing sections } & \multicolumn{2}{|r|}{ Beam sections } \\
\hline $\begin{array}{c}\text { Sec. } \\
\text { name }\end{array}$ & $\begin{array}{c}\text { Dimensions } \\
(\mathrm{mm})\end{array}$ & $\begin{array}{c}\text { Sec. } \\
\text { name }\end{array}$ & $\begin{array}{c}\text { Dimensions } \\
(\mathrm{mm})\end{array}$ & $\begin{array}{c}\text { Sec. } \\
\text { name }\end{array}$ & $\begin{array}{c}\text { Dimensions } \\
(\mathrm{mm})\end{array}$ \\
\hline C. 1 & Box: $150 \times 150 \times 10$ & BR.1 & Pipe : $100 \times 6$ & B. 1 & I-section : $250 \times 200 \times 12 \times 8$ \\
\hline C. 2 & Box: $150 \times 150 \times 12$ & BR.2 & Pipe : $100 \times 8$ & B. 2 & I-section : $250 \times 200 \times 15 \times 8$ \\
\hline C. 3 & Box: $200 \times 200 \times 12$ & BR.3 & Pipe : $120 \times 8$ & B. 3 & I-section : $300 \times 200 \times 15 \times 8$ \\
\hline C. 4 & Box: $200 \times 200 \times 15$ & BR.4 & Pipe : $150 \times 10$ & B. 4 & I-section : $300 \times 200 \times 20 \times 8$ \\
\hline C.5 & Box: $200 \times 200 \times 20$ & BR.5 & Pipe : $150 \times 12$ & B. 5 & I-section : $400 \times 250 \times 20 \times 10$ \\
\hline C. 6 & Box: $250 \times 250 \times 20$ & BR.6 & Pipe : $200 \times 12$ & B. 6 & I-section : $400 \times 300 \times 25 \times 10$ \\
\hline C. 7 & Box: $300 \times 300 \times 20$ & BR.7 & Pipe : $200 \times 15$ & B. 7 & I-section : $500 \times 250 \times 25 \times 10$ \\
\hline C. 8 & Box: $300 \times 300 \times 25$ & BR.8 & Pipe : $200 \times 20$ & B. 8 & I-section : $500 \times 300 \times 25 \times 10$ \\
\hline C.9 & Box: $300 \times 300 \times 30$ & BR.9 & Pipe : $250 \times 20$ & B.9 & I-section : $500 \times 300 \times 25 \times 10$ \\
\hline C. 10 & Box: $350 \times 350 \times 30$ & BR.10 & Pipe : $300 \times 20$ & B. 10 & I-section : $600 \times 300 \times 30 \times 10$ \\
\hline C.11 & Box: $400 \times 400 \times 30$ & BR.11 & Pipe : $300 \times 25$ & B.11 & I-section : $600 \times 300 \times 35 \times 10$ \\
\hline C.12 & Box: $400 \times 400 \times 35$ & BR.12 & Pipe : $300 \times 30$ & B.12 & I-section : $700 \times 300 \times 35 \times 10$ \\
\hline C.13 & Box: $400 \times 400 \times 40$ & BR.13 & Pipe : $300 \times 35$ & B.13 & I-section : $700 \times 375 \times 35 \times 10$ \\
\hline C. 14 & Box: $500 \times 500 \times 35$ & BR.14 & Pipe : $350 \times 35$ & B. 14 & I-section : $750 \times 400 \times 35 \times 10$ \\
\hline C. 15 & Box: $500 \times 500 \times 40$ & BR.15 & Pipe : $400 \times 35$ & B.15 & I-section : $800 \times 400 \times 35 \times 10$ \\
\hline C. 16 & Box: $550 \times 550 \times 40$ & & & & \\
\hline C.17 & Box: $600 \times 600 \times 40$ & & & & \\
\hline C. 18 & Box: $650 \times 650 \times 40$ & & & & \\
\hline C.19 & Box: $700 \times 700 \times 40$ & & & & \\
\hline C. 20 & Box: $700 \times 700 \times 50$ & & & & \\
\hline C. 21 & Box: $750 \times 750 \times 50$ & & & & \\
\hline C. 22 & Box: $800 \times 800 \times 50$ & & & & \\
\hline C. 23 & Box: $850 \times 850 \times 50$ & & & & \\
\hline C. 24 & Box: $850 \times 850 \times 60$ & & & & \\
\hline C. 25 & Box: $900 \times 900 \times 60$ & & & & \\
\hline C. 26 & Box: $950 \times 950 \times 60$ & & & & \\
\hline C. 27 & Box: $950 \times 950 \times 70$ & & & & \\
\hline
\end{tabular}

perature changing method is used. In this method, after restricting floor diaphragms from lateral displacement, first, temperature changes in bracing members so that the equivalent seismic forces are generated in the members. Then, for omitting the interaction of generated forces with equivalent axial stiffness forces, module of elasticity of bracing sections is reduced to a very small one $(E=0.1 \mathrm{MPa})$. Therefore, the generated forces in the bracing members remain constant due to temperature change. It should be noticed that alterations in other properties of the material could be beneficial to simplify the procedure. For example, if the Coefficient of Thermal Expansion would be set to 1 and $F_{y}=1 \mathrm{MPa}$, the thermal change needed in all tension resisting braces would be equal to $R_{y} \cdot F_{y}$. Although thermal change for compression resisting braces would be various for different member sections, the values would be more sensible to deal with.

\section{Evaluation of elastic response of different bracing systems}

The main goal of this paper is to investigate ductility reduction factor of different types of bracing systems, which are introduced in Figure 1. But, studying and comparing the elastic response of CBFs and double large-scale concentrically bracing frames can be useful in advance. So, in this part, elastic responses of 160 frames are presented and compared.

\subsection{Natural period}

Figures 2 and 3 show natural periods of 80 OCBFs and 80 SCBFs, respectively. According to Figures 2 and 3, the natural periods of CBF.1, CBF.3, and CBF.4 are very close to each other; the natural period of CBF.2 is significantly more than other braced frames; natural period of CBF.5 is significantly less than other braced 


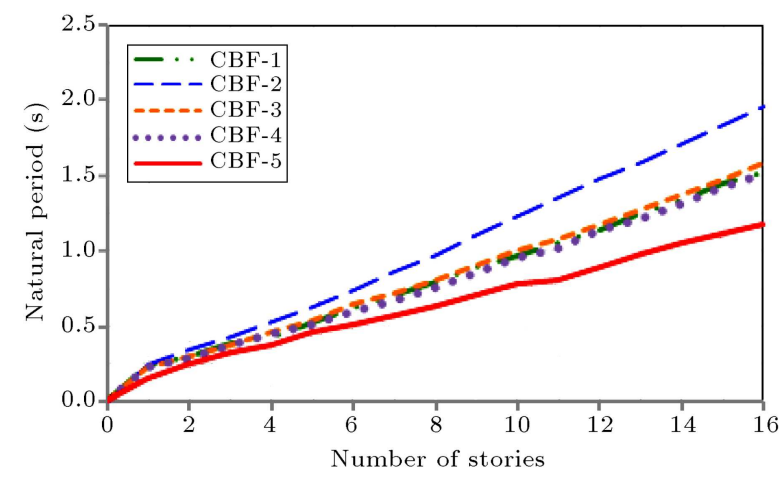

Figure 2. Natural period diagram according to the number of stories in OCBFs.

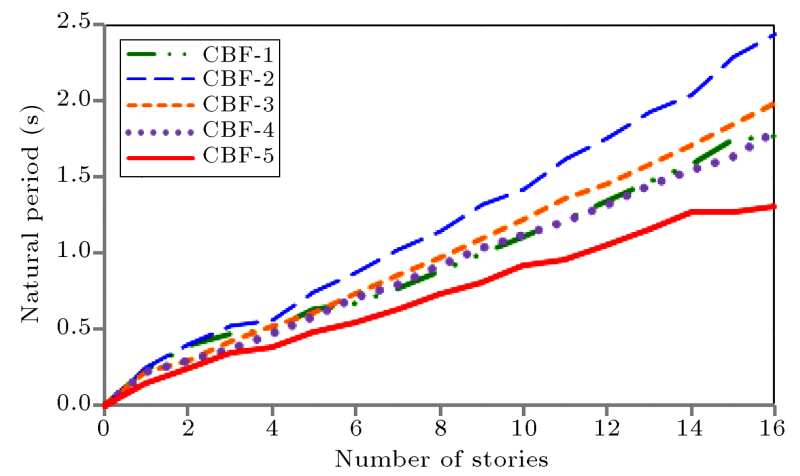

Figure 3. Natural period diagram according to the number of stories in SCBFs.

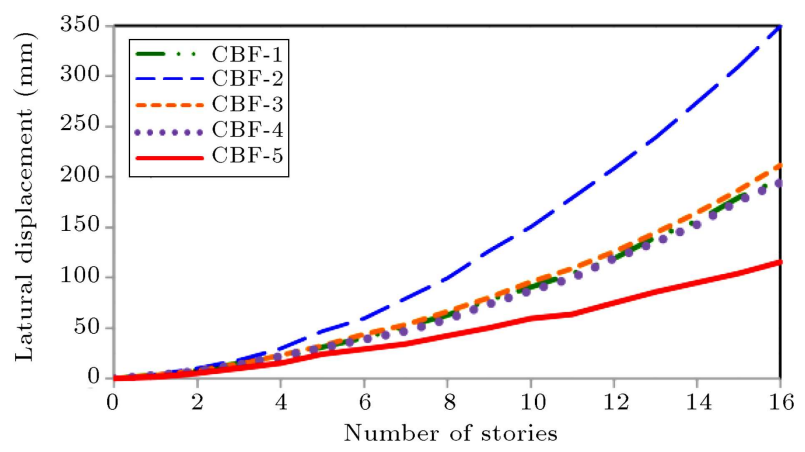

Figure 4. Maximum lateral displacement diagram according to number of stories in OCBFs.

frame's natural period. So, according to the plots, it can be concluded that frames, which are braced in two outer bays (CBF.2), are more flexible than other concentrically braced frames. And, double large-scale concentrically braced frames are always stiffer than the other concentrically braced frames.

\subsection{Maximum lateral displacement}

Figures 4 and 5 present maximum lateral displacements of $80 \mathrm{OCBFs}$ and $80 \mathrm{SCBFs}$, respectively. According to the displayed diagrams in Figures 4 and 5, maximum lateral displacement in X-braced frames, which are braced in two outer bays (CBF.2), is more than other bracing systems, and maximum lateral displace-

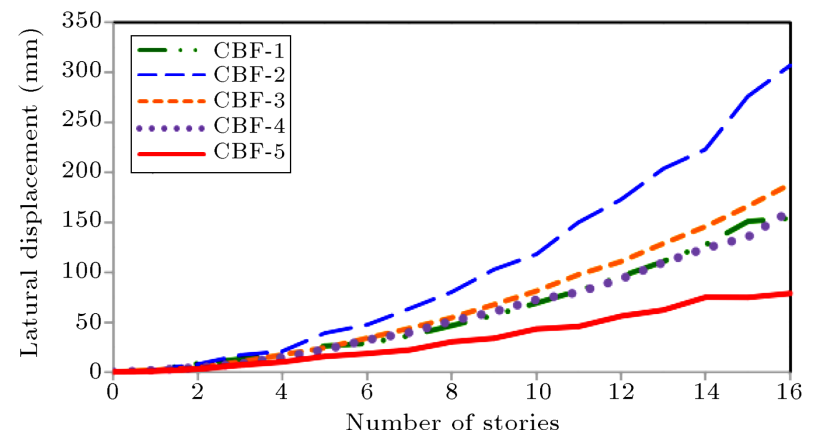

Figure 5. Maximum lateral displacement diagram according to number of stories in SCBFs.

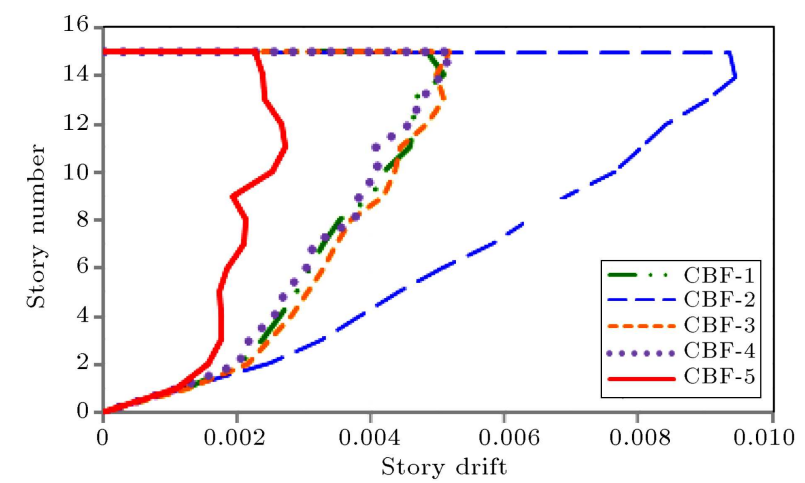

Figure 6. Drift distribution diagram in story level for a 15 -story frame with ordinary concentrically bracing system.

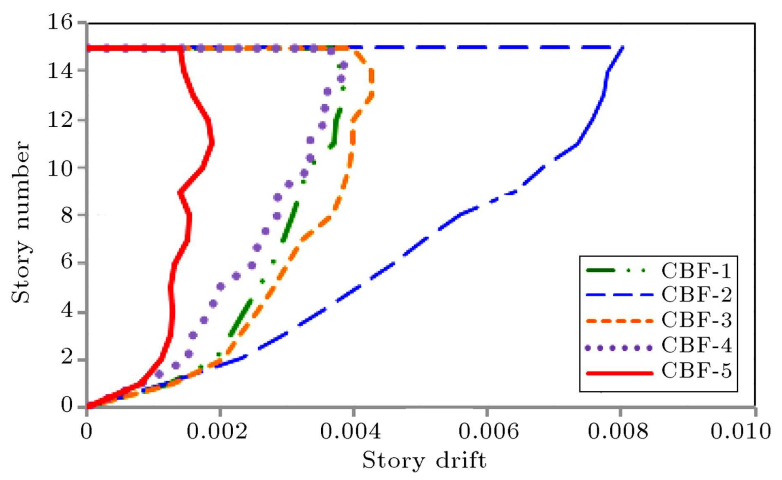

Figure 7. Drift distribution diagram in story level for a 15 -story frame with special concentrically bracing system.

ment of double large-scale concentrically braced frames (CBF.5) is always less than other ones.

Another element that should be considered is the drift distribution among the story levels.

Figures 6 and 7 display drift distribution of CBFs versus the height of 15-story frames, which are braced using different types of bracings and are designed for two types of ordinary and special ductility demands. According to the diagrams, and as expected, for frames with the bracing types of CBF.1 to CBF.4, the flexural behavior of bracing system is more noticeable than the shear behavior of columns; consequently, frames with bracing types of CBF.1 to CBF.4 have flexural behav- 


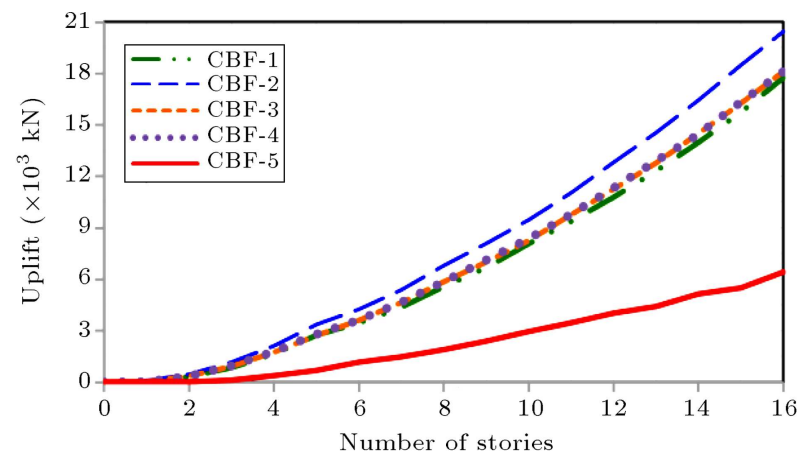

Figure 8. Uplift force diagram according to number of stories for OCBFs.

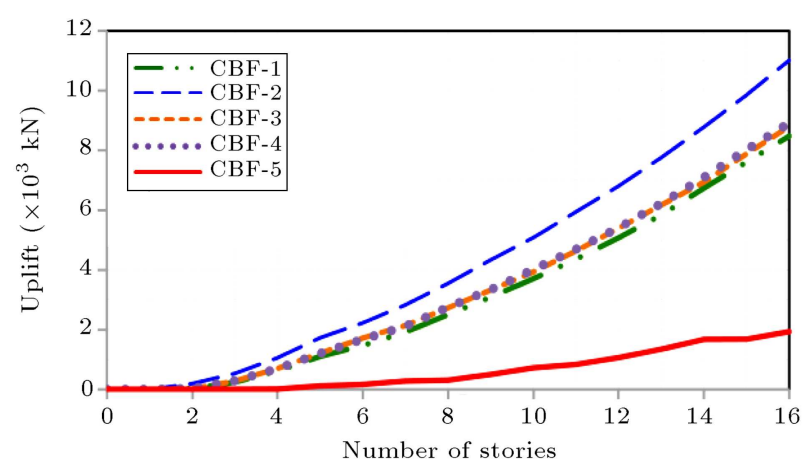

Figure 9. Uplift force diagram according to number of stories for SCBFs.

iors rather than shear behaviors. But, the behaviors of frames with double large-scale concentrically brace (CBF.5) are completely different from other types of bracing systems, because for this type of bracing, column's stiffness, which participate in total behavior of frames, is noticeable from other types of framing. So, the total behavior of this type of frames is very close to the shear behavior rather than the flexural one, and this can be mentioned as a benefit of using CBF.5 bracing system.

\subsection{Uplift force}

Figures 8 and 9 display uplift forces of 80 OCBFs and 80 SCBFs, respectively. According to the diagrams, the uplift force in the frames which are braced concentrically in two outer bays (CBF.2) is always a little more than the other bracing types. In addition, uplift force of frames with a double large-scale concentrically bracing system (CBF.5) is always less than that of other frames.

\subsection{Used steel weight}

Figures 10 and 11 illustrate used steel weight of 80 OCBFs and $80 \mathrm{SCBFs}$, respectively. According to the diagrams, used steel weights of braced frames for 5 stories are close to each other, but for frames with more than 5 stories, used steel weight for bracing type 2 (CBF.2) is increased significantly in comparison with other bracing types. Also, for frames with more than 5

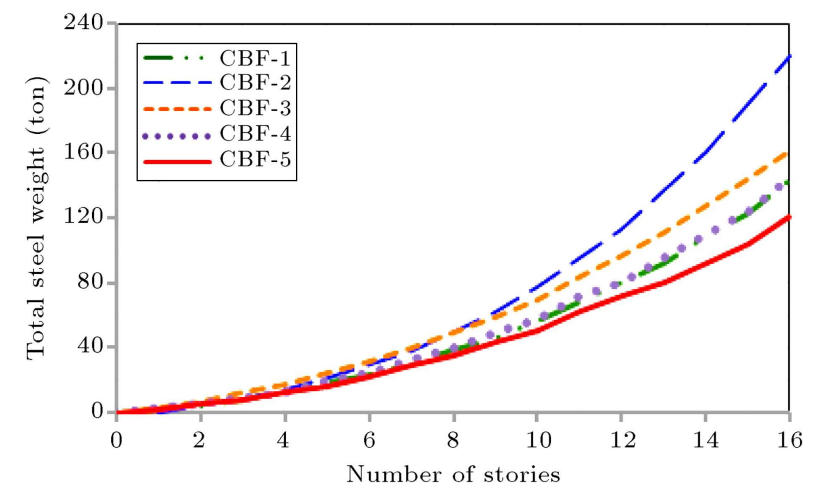

Figure 10. Used steel diagram according to number of stories for OCBFs.

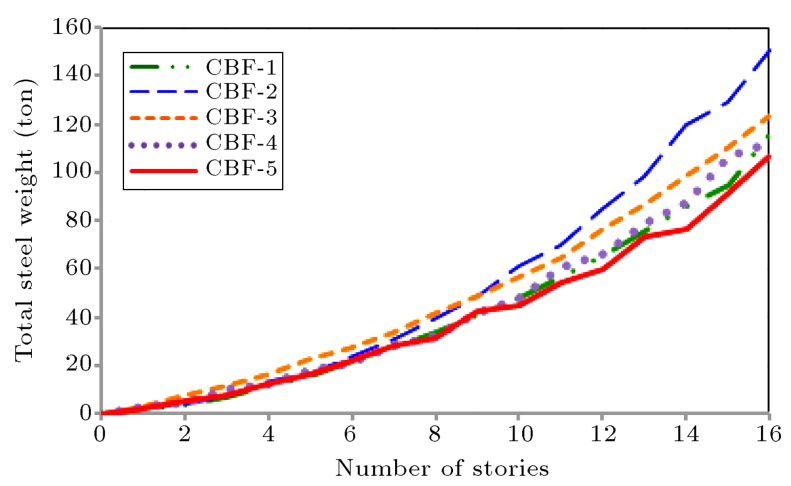

Figure 11. Used steel diagram according to number of stories for SCBFs.

stories, used steel weight for frames with bracing type 5 (CBF.5) is less than other braced frames.

\section{Literature review of response modification factor}

Ductility reduction factor is defined as the ductility capacity of the structure in inelastic response to the severe earthquakes and is modified as the ratio of the maximum displacement of the structure without any collapse to the yield displacement:

$$
\mu=\frac{\delta_{u}}{\delta_{y}}
$$

In most of earthquake resisting design codes, response modification factor is made up of three components as overstrength, redundancy, and ductility. The effects of these parameters are displayed in Figure 12 for structures which are designed according to LRFD method. Based on the plot, response modification factor can be calculated using the following equation:

$$
R=\Omega R_{\mu}
$$

where $\Omega$ is defined as the ratio between $V_{y}$ (the force needed to reach yield limit and collapse mechanism or the force corresponding to target displacement and 


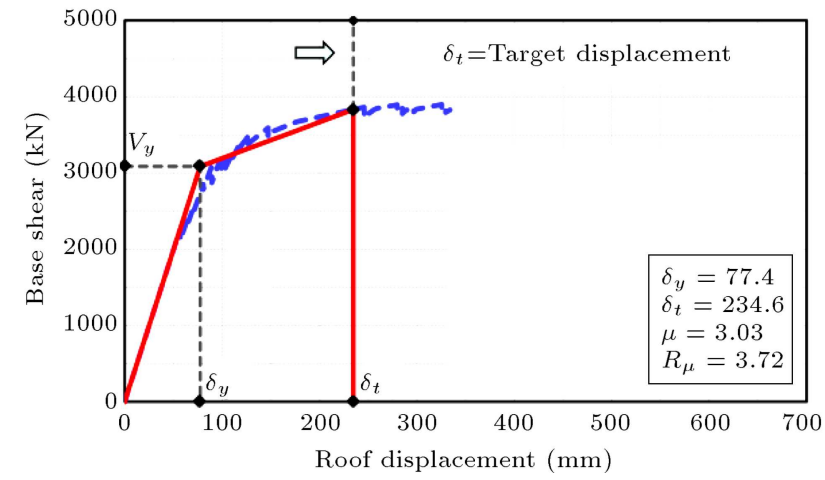

Figure 12. Capacity curve of SCBF-1 (10-story).

$V_{s}$ (the force needed for formation of the first plastic hinge):

$$
\Omega=\frac{V_{y}}{V_{s}}
$$

The overstrength factor depends on many parameters. For ordinary concentrically braced frames, ASCE7 proposed value is equal to 2 for the overstrength factor.

Ductility reduction factor, $R_{\mu}$, is defined as the ratio between the ultimate elastic force to the yield point force of structure:

$$
R_{\mu}=\frac{V_{e}}{V_{y}}
$$

If the overstrength factor of the ordinary concentrically braced frames is supposed to be equal to 2 , then the minimum ductility reduction factor can be calculated from the following equations:

a) For ordinary concentrically braced frames:

$$
R=3.5 \Rightarrow R_{\mu} \geq \frac{3.5}{2} \Rightarrow R_{\mu} \geq 1.75
$$

b) For special concentrically braced frames:

$$
R=5.5 \Rightarrow R_{\mu} \geq \frac{5.5}{2} \Rightarrow R_{\mu} \geq 2.75 \text {. }
$$

According to FEMA-356 [24], nonlinear static analysis (pushover analysis) is one of the most acceptable procedures to evaluate the ductility reduction factor of structures. In recent years, there have been many works concerning the evaluation of ductility reduction factor of structures as follows:

1. A method based on equality of displacements and the equality of area under the force-displacement curve.

2. According to this method, for structural systems with natural periods of more than 1 second, the maximum displacement of elastic and inelastic responses are very close to each other. So, ductility reduction factor, $R_{\mu}$, can be calculated using the following equation:

$$
R_{\mu}=\mu \text {. }
$$

Also, for structural systems with a natural period of less than 0.5 seconds, the assumption of elasticperfectly plastic behavior and that of equality under the curve areas of the presumed elastic and inelastic responses can be calculated using the following equation:

$$
R_{\mu}=\sqrt{(2 \mu-1)}
$$

3. Newmark and Hall's method. The phenomenon used for NewMark and Hall's method is the same as methods based on the equality of displacements for the elastic and inelastic responses of structures with the assumption of elastic-perfectly plastic behavior with a little difference in periods between 0.5 and 1 seconds $[25,26]$;

4. Mirenda and Bertero method. According to this method, ductility reduction factor can be calculated using the following equation [27-29]:

$$
R_{\mu}=\frac{\mu-1}{\Phi}+1 \geq 1
$$

In the above equation, $\Phi$ depends on the soil type and can be calculated for alluvium sites using the following equation:

$$
\Phi=1+\frac{1}{12 T-\mu T}-\frac{2}{5 T} e^{-2(\ln (T)-0.2)^{2}} .
$$

According to FEMA-356, for calculating ductility reduction factor, first, the target displacement should be calculated. Then, the capacity curve, obtained from pushover analysis, should be idealized and ductility reduction factor can be calculated using idealized capacity curve. Target displacement shall be calculated in accordance with the following equation:

$$
\delta_{t}=C_{0} C_{1} S_{a} \frac{T_{e}^{2}}{4 \pi^{2}} g
$$

where, $C_{0}$ is modification factor to relate spectral displacement of an equivalent single-degree freedom system to the roof displacement of the building with multi-degree freedom and can be calculated using the following equation:

$$
C_{0}=\varphi_{1, r} \frac{\sum_{i=1}^{n} W_{i} \varphi_{1, i}}{\sum_{i=1}^{n} W_{i} \varphi_{1, i}^{2}},
$$

where, $W_{i}$ is the effective seismic weight and $\varphi_{1, i}$ is the shape vector's corresponding member for the corresponding elevation. $C_{1}$ is the modification factor to relate the expected maximum inelastic displacement 
to displacements calculated for linear elastic response and can be calculated using the following equation:

$$
\begin{aligned}
& T_{e} \geq T_{s} \Rightarrow C_{1}=1, \\
& T_{e}<T_{s} \Rightarrow C_{1}=\left[1+/\left(R_{d}-1\right) T_{s} / T_{e}\right] / R_{d},
\end{aligned}
$$

where, $T_{e}$ is the effective period of structure and can be calculated using the following equation:

$$
T_{e}=T_{i} \sqrt{\frac{K_{i}}{K_{e}}}
$$

where, $T_{i}$ is the elastic period, $K_{i}$ is the elastic stiffness of structure, and $K_{e}$ is the effective stiffness of the structure. $R_{d}$ can be calculated using the following equation:

$$
R_{d}=\frac{S_{a} W}{V_{y}},
$$

where, $S_{a}$ is the response spectrum acceleration at the effective period.

For calculating target displacement using Eq. (11), capacity curve, which displays the relationship between base shear and corresponding displacement, should be bilinearized so that first, yield strength, $V_{y}$ and corresponding yield displacement ( $V_{y}$ and $\delta_{y}$, respectively) can be calculated. Then, according to the calculated parameters, effective fundamental period should be obtained.

Usually, bilinear curve starts with an initial slope, $K_{e}$, which should be taken as the secant stiffness calculated at a base shear force equal to $60 \%$ of effective yield strength of the structure; the effective yield strength should not be taken as more than the maximum base shear force at any arbitrary point along the capacity curve. The second line of bilinear curve represents the positive slope after the structures yield and starts from the points $\left(\delta_{u}, V_{u}\right)$, and another point along the line to the points $\left(\delta_{u}, V_{u}\right)$ so as to balance the area between the above and below of the capacity and bilinear curves.

As mentioned previously, it seems that substituting the capacity curve with a bilinear curve is an iterative procedure, but because the behavior of the structure remains linear between formations of two plastic hinge, yield strength and corresponding yield displacement of structure can be obtained from a closed form solution.

In this study, a small program is prepared by the authors, which can be used to obtain the bilinear curve.

One of the most important steps of pushover analysis is defining force-displacement relationships of the structural elements. Actually, the inelastic behavior of any structural member should be obtained through an experimental procedure. But, as mentioned in FEMA 356, instead of using experimental methods, acceptance criteria, which are clearly defined in FEMA 356 , can be used for evaluating the deformation capacity of structural members. In this study, FEMA's equations are used for modeling inelastic relation of force- displacement.

For modeling inelastic force-deformation relationships, it is assumed that inelastic deformation of members concentrate on plastic hinges, and the behaviors of other parts of the member remain elastic. If more refined model or local information is required, then a Fiber-base approach should be used. This is an approach classically validated in many applications: experimental results (e.g., [30]), modeling structural frames in seismic analyses of steel structures [31,32], reinforced concrete buildings [33], extreme loading [34], and connections $[35,36]$.

For flexural members (beams and columns), plastic hinges are assigned to the start and end of structural components or to the specific point load locations; these hinges can be from type $\mathrm{M}, \mathrm{V}$, or an interaction hinges of P-M. Hinge type $\mathrm{P}$ can be used for axial elements like bracing and columns which have axial behavior and can be assigned to the middle of the member.

In the first section of this part, different methods of calculating ductility reduction factor are discussed; each of mentioned methods has some advantages and disadvantages. For example, Eq. (7) can only be used for structures with a fundamental period more than 1 second. Also, Eq. (8) can only be used for structures with a fundamental period of less than 0.5 second. Because fundamental periods of most of the studied structures in this paper are between 0.5 and 1 seconds, it is not recommended to calculate the fundamental period using Eqs. (7) and (8).

Nowadays, both of ductility reduction factor methods are used by researchers, but Miranda and Bertero's method is used in this paper due to its popularity.

\section{Pushover analysis and ductility reduction factor calculation}

In this paper, about 160 steel frames, 1 to 16 stories, with a concentrically bracing system are comprehensively studied for evaluating the sensitivity of frames to the types of bracing systems and also formation of bracings in the height of the structure; 80 frames which are studied are ordinary concentrically braced frames (OCBFs); the other 80 frames are special concentrically braced frames (SCBFs).

Because giving detailed calculation account of ductility reduction factor will take more pages of the paper, important parameters which are used for calculating ductility reduction factor of some types of 
Table 2. Important parameters for calculating ductility reduction factor.

\begin{tabular}{|c|c|c|c|c|c|c|c|c|c|c|c|c|c|c|}
\hline \multicolumn{3}{|c|}{$\begin{array}{c}\text { Frame type \& } \\
\text { number of stories }\end{array}$} & $\begin{array}{l}T_{e} \\
(\mathrm{~s})\end{array}$ & $C_{0}$ & $C_{1}$ & $S_{a}$ & $\begin{array}{c}\delta_{t} \\
(\mathrm{~mm})\end{array}$ & $\begin{array}{c}\delta_{y} \\
(\mathrm{~mm})\end{array}$ & $\begin{array}{c}V_{y} \\
(\mathrm{kN})\end{array}$ & $\begin{array}{c}\delta_{u} \\
(\mathrm{~mm})\end{array}$ & $\begin{array}{c}V_{u} \\
(\mathrm{kN})\end{array}$ & $\mu$ & $\Phi$ & $\mu$ \\
\hline \multirow{10}{*}{ 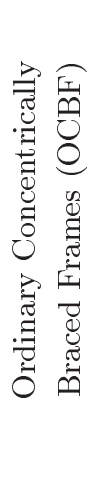 } & \multirow{5}{*}{ 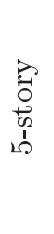 } & CBF-1 & 0.523 & 1.38 & 1.00 & 0.849 & 79.6 & 23.7 & 2509 & 46.9 & 3193 & 1.98 & 1.01 & 1.97 \\
\hline & & CBF-2 & 0.624 & 1.41 & 1.00 & 0.755 & 103 & 38.8 & 2760 & - & 3219 & 2.66 & 0.912 & 2.82 \\
\hline & & CBF-3 & 0.541 & 1.37 & 1.00 & 0.830 & 82.7 & 25.2 & 2559 & 52.5 & 3058 & 2.08 & 0.99 & 2.09 \\
\hline & & $\mathrm{CBF}-4$ & 0.516 & 1.39 & 1.00 & 0.857 & 78.8 & 27.4 & 2926 & 44.3 & 3240 & 1.61 & 1.01 & 1.60 \\
\hline & & CBF-5 & 0.467 & 1.34 & 1.05 & 0.875 & 66.7 & 12.9 & 1757 & 26.3 & 3053 & 2.04 & 1.08 & 1.96 \\
\hline & \multirow{5}{*}{$\begin{array}{l}2 \\
\overrightarrow{0} \\
\substack{0 \\
0 \\
\infty \\
\infty}\end{array}$} & CBF-1 & 0.790 & 1.45 & 1.00 & 0.645 & 145 & 49.5 & 3270 & 83.6 & 4064 & 1.69 & 0.78 & 1.89 \\
\hline & & CBF-2 & 0.971 & 1.48 & 1.00 & 0.562 & 194.9 & 90.9 & 3871 & - & 4306 & 2.14 & 0.73 & 2.55 \\
\hline & & CBF-3 & 0.810 & 1.45 & 1.00 & 0.634 & 149.9 & 61.9 & 3965 & 83.4 & 4061 & 1.35 & 0.76 & 1.46 \\
\hline & & CBF-4 & 0.754 & 1.47 & 1.00 & 0.665 & 138.1 & 67.5 & 4783 & 67.8 & 4802 & 1.00 & 0.79 & 1.00 \\
\hline & & CBF-5 & 0.634 & 1.44 & 1.00 & 0.747 & 107.4 & 39.9 & 4193 & 51.2 & 3979 & 1.28 & 0.88 & 1.32 \\
\hline \multirow{10}{*}{ 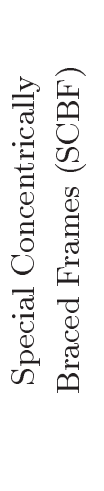 } & \multirow{5}{*}{ 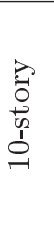 } & CBF-1 & 1.115 & 1.48 & 1.00 & 0.513 & 234.6 & 77.4 & 3086 & - & 3830 & 3.03 & 0.75 & 3.72 \\
\hline & & CBF-2 & 1.424 & 1.49 & 1.00 & 0.435 & 326.6 & 122.8 & 2911 & 285 & 3309 & 2.32 & 0.80 & 2.64 \\
\hline & & $\mathrm{CBF}-3$ & 1.229 & 1.45 & 1.00 & 0.480 & 261.2 & 71.2 & 2445 & 239.9 & 2656 & 3.37 & 0.77 & 4.08 \\
\hline & & $\mathrm{CBF}-4$ & 1.131 & 1.48 & 1.00 & 0.508 & 239 & 91.3 & 3465 & - & 3496 & 2.62 & 0.74 & 3.18 \\
\hline & & CBF-5 & 0.926 & 1.39 & 1.00 & 0.580 & 171.8 & 49.7 & 3153 & - & 3635 & 3.46 & 0.76 & 4.25 \\
\hline & \multirow{5}{*}{ 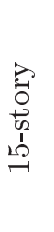 } & CBF-1 & 1.757 & 1.51 & 1.00 & 0.379 & 439 & 139.2 & 3179 & 350 & 3895 & 2.52 & 0.89 & 2.72 \\
\hline & & $\mathrm{CBF}-2$ & 2.296 & 1.55 & 1.00 & 0.317 & 643.6 & 250.3 & 3227 & 406.9 & 3686 & 1.63 & 0.96 & 1.65 \\
\hline & & CBF-3 & 1.849 & 1.50 & 1.00 & 0.366 & 466.4 & 158.9 & 3349 & 403.7 & 2953 & 2.54 & 0.90 & 2.70 \\
\hline & & CBF-4 & 1.637 & 1.53 & 1.00 & 0.397 & 404.5 & 181 & 4666 & - & 5138 & 2.23 & 0.86 & 2.44 \\
\hline & & CBF-5 & 1.283 & 1.45 & 1.00 & 0.467 & 277 & 95.4 & 4570 & - & 5696 & 2.90 & 0.78 & 3.45 \\
\hline
\end{tabular}

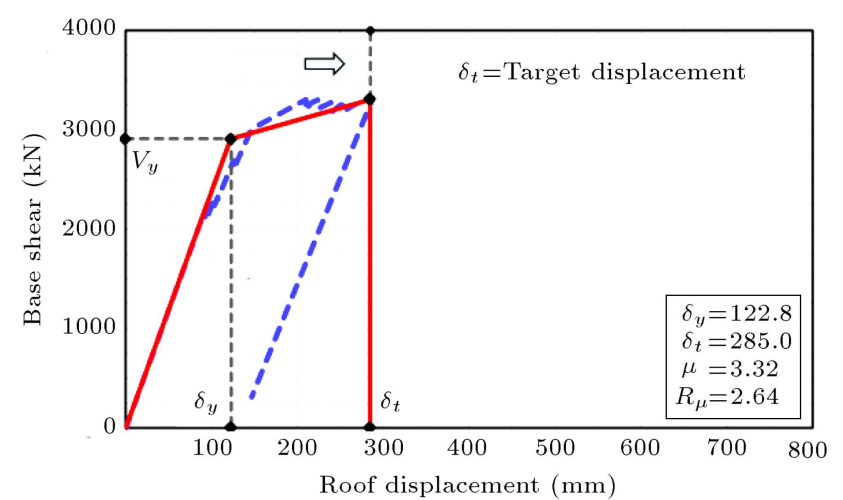

Figure 13. Capacity curve of SCBF-2 (10-story).

frames are given in Table 2. Also, from numerous models which are used in this study, capacity curves of only one series of frames are illustrated within Figures 12 to 16 .

It should be noticed that in part 7 of the paper, all of the results of $160 \mathrm{CBFs}$ are reviewed and discussed completely.

\section{Remarks on results}

In this section, the results of nonlinear static analysis (push over analysis) for OCBFs and SCBFs are presented.

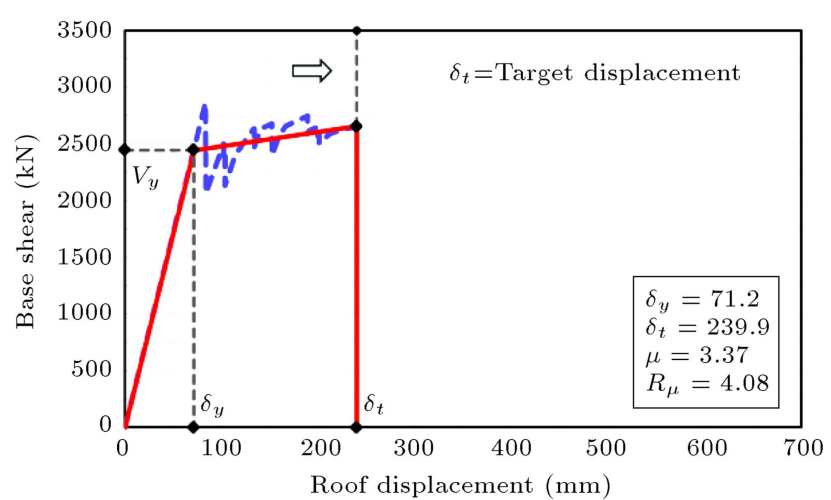

Figure 14. Capacity curve of SCBF-3 (10-story).

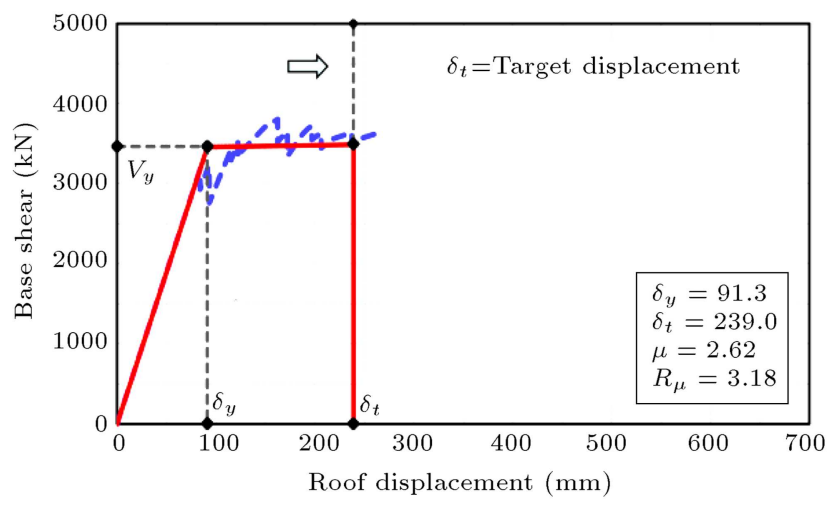

Figure 15. Capacity curve of SCBF-4 (10-story). 


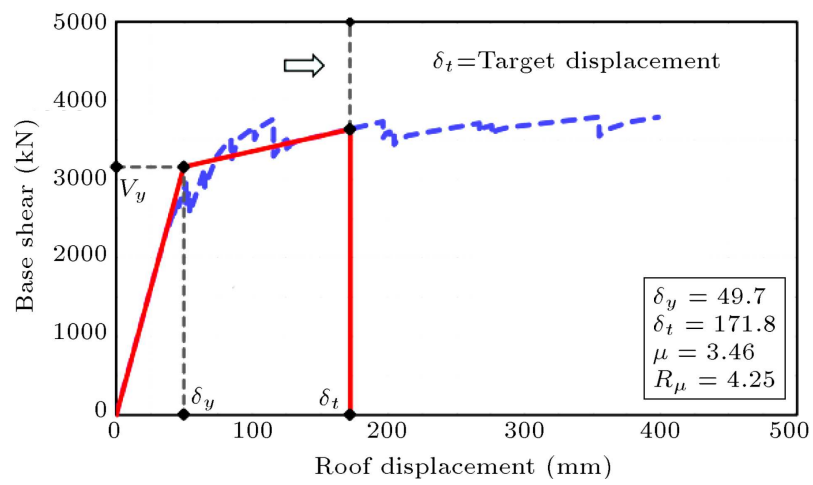

Figure 16. Capacity curve of SCBF-5 (10-story).

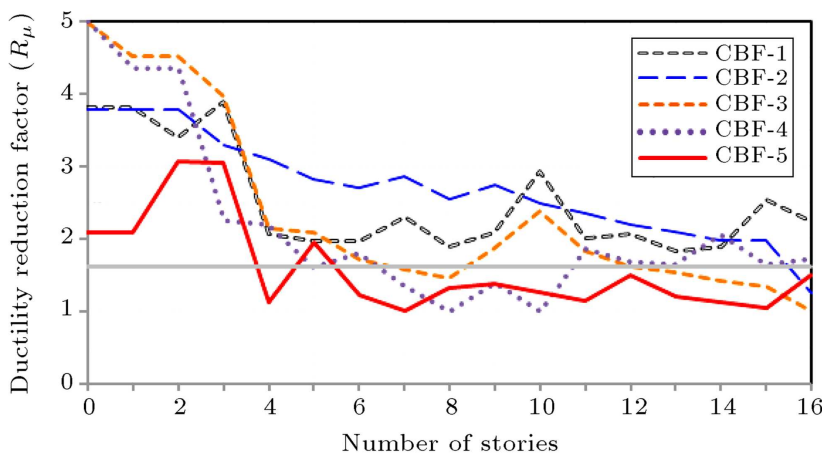

Figure 17. Ductility reduction diagram for different types of ordinary bracing.

\subsection{Ordinary Concentrically Brace Frames (OCBFs)}

Figure 17 displays diagram for ductility reduction factor of 80 ordinary concentrically braced frames. As it is illustrated, braced frames of type OCBF.2 have the maximum ductility reduction factor; braced frames of type OCBF.5 have the minimum ductility reduction factor. But, as discussed previously in the elastic response analysis of frames, braced frames of type OCBF. 5 had better elastic responses than braced frames of type OCBF.2.

According to diagrams which are displayed in Figure 17 , obtained ductility reduction factor for braced frames of types OCBF. 1 to OCBF. 3 with 1 to 16 stories is more than expected ductility reduction factor which is proposed by ASCE7 (ASCE7: $R_{\mu-\text { Required }}=$ $R / \Omega_{0}=3.5 / 2=1.75$ ), because the level of designing forces in this type of bracing frames. Therefore, the maximum allowable height of the frames with bracing types OCBF.1 to OCBF.3 can be more than ASCE7's proposed one.

For frames with bracing type OCBF.4 and taller than 5 stories, expected ductility reduction factor cannot be obtained. So, according to the results, maximum allowable heights of these kinds of braced frames can be increased up to 5 stories $(16 \mathrm{~m})$.

For braced frames of type OCBF. 5 and for frames taller than 3 stories, expected ductility reduction factor

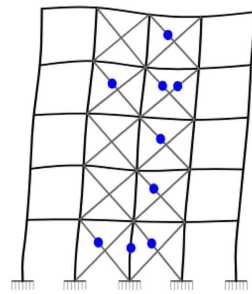

(a) OCBF-1 \& 5-story

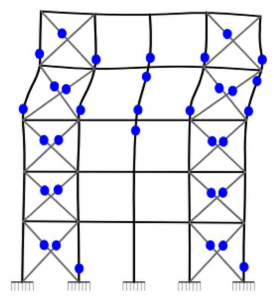

(b) OCBF-2 \& 5-story

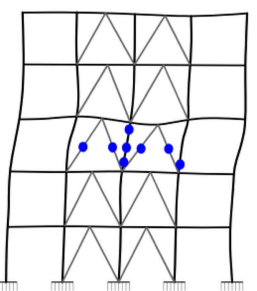

(c) OCBF-3 \& 5-story

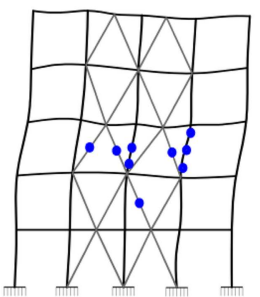

(d) OCBF-4 \& 5-story

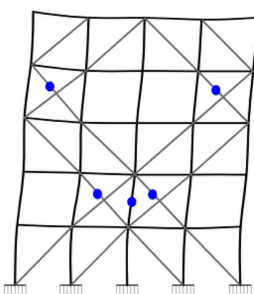

(e) OCBF-5 \& 5-story
Figure 18. One of the collapse mechanisms of ordinary concentrically braced frames (5-story).

cannot be obtained, and ductility reduction factor for frames taller than 3 stories is always less than 1.75 , which cannot accommodate ASCE7's expected ductility. So, according to the results of this study, the maximum allowable height of OCBF.5 is 10.7 meters. (3 stories).

One of the imperfections of studied bracing types is that most of the capacity curves which are displayed in Figures 12 to 16 cannot reach their target displacement, so they collapse before getting to the expected target displacement according to the mechanisms displayed in Figure 18. But, despite such imperfections, because of high design strength of these types of bracing systems, expected ductility can be achieved.

\subsection{Special Concentrically Braced Frames ( $S C B F s$ )}

Figure 19 displays diagram for ductility reduction factor of 80 special concentrically-braced frames. As this figure illustrates, braced frames of types SCBF-1, $\mathrm{SCBF}-3$, and SCBF-4 have the same ductility reduction

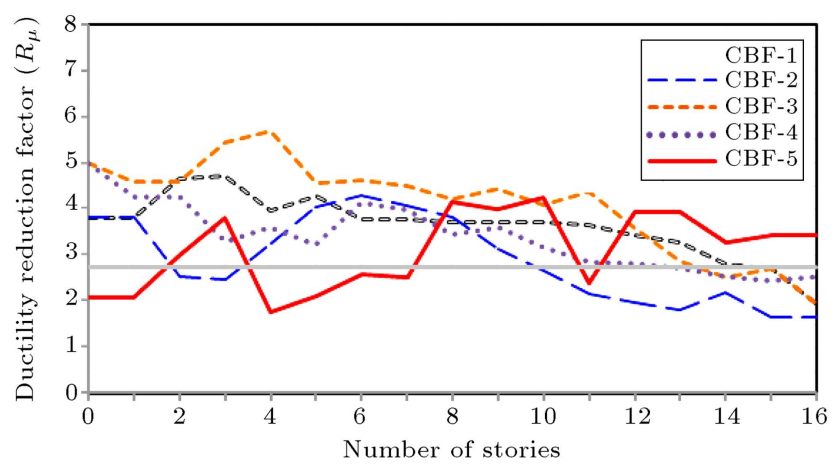

Figure 19. Ductility reduction diagram for different types of special bracing. 
factor, but the ductility reduction factor of bracing types SCBF-2 and SCBF-5 differs from others.

According to the diagrams which are displayed in Figure 19, braced frames of types SCBF-1, SCBF3 , and SCBF-4 cannot achieve their expected ductility (ASCE7: $R_{\mu \text {-Required }}=R / \Omega_{0}=5.5 / 2=2.75$ ). So, according to the results of this paper, for these sorts of braced frames with more than 12 stories, response modification factor should be less than 5.5.

For braced frames of type SCBF-2 which are taller than 9 stories, expected ductility cannot be achieved. In other words, from ductility point of view, these frames are in an ill condition in comparison with frames with bracing types SCBF-1, SCBF-3, and SCBF-4. So, for frames with bracing type $\mathrm{SCBF}-2$, which are more than 9 stories, response modification factor should be less than 5.5.

Unfortunately, braced frames of type SCBF- 5 are in ill condition for achieving ductility point of view, because as displayed in figure 19, in these sorts of braced frames for frames up to 7 stories, expected ductility cannot be achieved. And, this can be one of the most important imperfections for this kind of bracing system. But, it should be taken into consideration that according to elastic response results, the use of bracing type $\mathrm{SCBF}-5$ reduces used steel weight. So, using a response modification factor, which is less than 5.5 for designing these frames, can probably save used steel in comparison with other types of bracings. Also, results confirm that despite other types of braced frames, SCBF-5 can achieve its expected ductility demand when the height of frame exceeds 7 stories.

As Figure 20 illustrates, another crucial point is that all SCBFs are redesigned and controlled according to seismic design provisions. For frames higher than 10 stories, the maximum inelastic displacement is lower than the target displacement and frames collapse before reaching it. Therefore, a revision is needed in this aspect, that is, to reduce the ductility reduction factor for SCBFs higher than 10 stories.

\section{Conclusion}

Results of analysis, design, and nonlinear static analysis (pushover analysis) of 160 ordinary concentricallybraced frames, which are braced with different types and formation of bracing systems in the height of the frames, are as follows:

1. The natural period of braced frames of types CBF$1, \mathrm{CBF}-3$, and CBF-4 are very close to each other, but the natural period of braced frame type CBF2 is significantly more than the natural period of other types of bracing systems and also the natural period of CBF-5 is significantly less than others;

2. Maximum lateral displacement of frames with bracing type $\mathrm{CBF}-2$ is always more; frames with bracing type CBF-5 are always less than maximum lateral displacements of other bracing systems;

3. Uplift force for frames with bracing type CBF-2 is always a little more than the uplift force in other types of bracing systems and uplift force for frames with bracing type CBF-5 is always much less than other braced frames' uplift force;

4. Weight of the used steel for frames with bracing types CBF-2 and CBF-5 is mostly more and less than the weight of used steel in other bracing types, respectively;

5. Ductility reduction factor for frames with bracing types OCBF-1, OCBF-2, and OCBF-3 is always more than expected ductility reduction factor (ASCE7: $R_{\mu-\text { Required }}=R / \Omega_{0}=3.25 / 2=1.625$ ) even for 16 stories frames. Also, the maximum allowable height of these types of braced frames can exceed ASCE7's proposed maximum allowable height;

6. For frames with bracing type OCBF-4 and for frames with more than 5 stories, expected ductility reduction factor cannot be achieved, but for frames up to 5 stories, expected ductility can be achieved. So, the maximum allowable height for these types

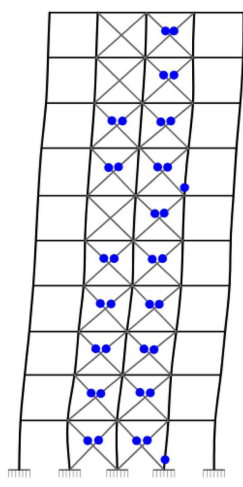

(a) SCBF-1 \& 10-story

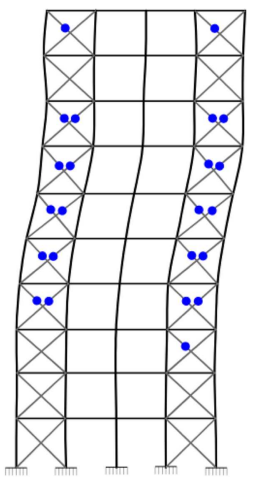

(b) SCBF-2 \& 10-story

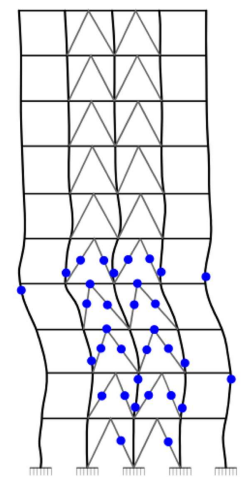

(c) SCBF-3 \& 10-story

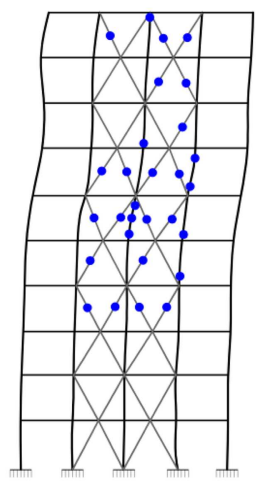

(d) SCBF-4 \& 10-story

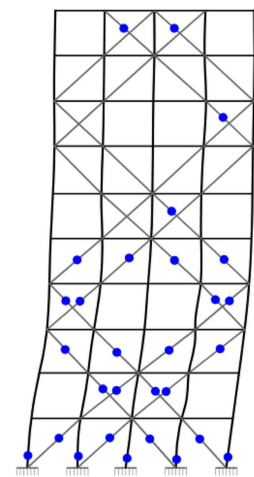

(e) SCBF-5 \& 10-story.

Figure 20. One of the collapse mechanisms of special concentrically braced frames (10-story). 
of braced frames can be increased up to 5 stories $(16 \mathrm{~m})$;

7. For frames with bracing type OCBF-5 and for frames with more than 3 stories, expected ductility reduction factor cannot be achieved. But, for frames up to 3 stories, expected ductility can be achieved. So, the maximum allowable height of these types of braced frames cannot exceed the ASCE7's one;

8. For frames with bracing types SCBF-1, SCBF3 , and SCBF-4 and with more than 12 stories, expected ductility reduction factor (ASCE7: $R_{\mu \text {-Required }}=R / \Omega_{0}=5.5 / 2=2.75$ ) cannot be achieved. But, for frames up to 12 stories, expected ductility can be achieved. So, for these types of braced frames, the maximum allowable height should be decreased to 12 stories, or a smaller value of response modification factor should be used for frames with more than 12 stories;

9. For frames with bracing type SCBF-2 and with more than 9 stories, expected ductility reduction factor cannot be achieved. But, for frames up to 9 stories, expected ductility can be achieved. So, for these types of braced frames, the maximum allowable height should decrease to 9 stories or a smaller value of response modification factor should be used for frames with more than 9 stories;

10. For frames with bracing type SCBF-5 and up to 7 stories, expected ductility reduction factor cannot be achieved. But, for frames more than 7 stories, expected ductility can be achieved. So, for these types of braced frames, especially for frames up to 7 stories, smaller value of response modification factor should be used.

\section{References}

1. Abazar Asghari, A. and Gandomi, A.H. "Ductility reduction factor and collapse mechanism evaluation of a new steel knee braced frame", Structure and Infrastructure Engineering Journal, Taylor and Francis (2015). DOI: 10.1080/15732479.2015.1009123

2. Wijesundara, K.K., Nascimbene, R. and Rassati, G.A. "Modeling of different bracing configurations in multistorey concentrically braced frames using a fiberbeam based approach", Journal of Constructional Steel Research, 101, pp. 426-436 (2014).

3. Wijesundara, K.K., Bolognini, D., Nascimbene, R. and Calvi, G.M. "Review of design parameters of concentrically braced frames with RHS shape braces", Journal of Earthquake Engineering, 13(1 SUPPL. 1), pp. 109-131 (2009).

4. Wijesundara, K.K., Nascimbene, R. and Sullivan, T.J. "Equivalent viscous damping for steel concentrically braced frame structures", Bulletin of Earthquake Engineering, 9(5), pp. 1535-1558 (2011).
5. ATC., Tentative Provisions for the Development of Seismic Regulations for Buildings, ATC-3-06, Applied Technology Council, Redwood City, California, pp. 4553 (1978).

6. ATC, Structural Response Modification Factors, ATC19, Applied Technology Council, Redwood City, California, pp. 5-32 (1995).

7. American Society of Civil Engineers (ASCE7), Minimum Design Loads for Buildings and Other Structures (2010).

8. American Institute of steel construction (AISC-341), Seismic Provisions for Structural Steel Buildings (2010).

9. Uriz, P., Filippou, F.C. and Mahin, S.A. "Model for cyclic inelastic buckling of steel braces", J. Struct. Eng., 134(4), pp. 619-628 (2008).

10. Uriz, P. and Mahin, S.A. "Toward earthquake-resistant design of concentrically braced steel-frame structures", PEER-2008/08, Pacific Earthquake Engineering Research Center (PEER), University of California, Berkeley, CA (2008).

11. Uang, C.M. and Nakashima, M. "Steel buddingrestrained braced frames", Chapter 16, Earthquake Engineering, From Engineering Seismology to Performance-Based Engineering, Y. Bozorgnia and V.V. Bertero, Eds., CRC Press, Boca Raton, FL (2004).

12. Black, R.G. Wenger, W.A.B. Popov, E.P. "Inelastic buckling of steel struts under cyclic load reversals", Report No. UCB/EERC-80/40, Earthquake Engineering Research Center, University of California at Berkeley (1980).

13. Uang, C.M. and Bertero, V.V. "Earthquake simulation tests and associated studies of a 0.3 -scale model of a 6-story concentrically braced steel structure", Report No. UCB/EERC-86/10, Earthquake Engineering Research Center, University of California at Berkeley (1986).

14. Whittaker, A.S., Uang, C.M. and Bertero, V.V. "An experimental study of the behavior of dual steel systems", Report No. UCB/EERC-88/14, Earthquake Engineering Research Center, University of California at Berkeley (1990).

15. Khatib, I.F., Mahin, S.A. and Pister, K.S. "Seismic behavior of concentrically braced steel frames", Report No. UCB/EERC-88/01, Earthquake Engineering Research Center, University of California at Berkeley (1988).

16. Roeder, C.W. "Seismic behavior of concentrically braced frame", Journal of Structural Engineering, $A S C E, \mathbf{1 1 5}(8)$, pp. 1837-56 (1989).

17. Remennikov, A.M. and Walpole, W.R. "Analytical prediction of seismic behavior for concentrically-braced steel systems", Earthquake Engineering and Structural Dynamics, 26(8), pp. 859-74 (1997).

18. Tremblay, R. "Inelastic seismic response of steel bracing members", Journal of Constructional Steel Research, 58(5-8), pp. 665-701 (2002). 
19. Balendra, T. and Huang, X. "Overstrength and ductility factors for steel frames designed according to BS 5950", Journal of Structural Engineering, ASCE, 129(8), pp. 1019-35 (2003).

20. Kim, J. and Choi, H. "Response modification factors of chevron-braced frames", Engineering Structures, 27, pp. 285-300 (2005).

21. BHRC, Iranian Code of Practice for Seismic Resistant Design of Buildings, Standard No. 2800 (3rd Edition) Building and Housing Research Center (2005).

22. ETABS, Integrated Building Design Software, nonlinear version 9.7.3, Berkeley (California), USA: Inc. (1995).

23. American Institute of Steel Construction (AISC360), Specification for Structural Steel Buildings (2010).

24. Federal Emergency Management Agency (FEMA), "Prestandard and Commentary for the Seismic Rehabilitation of Buildings", (FEMA 356), Washington, DC, November (2000).

25. Balendra, T. and Huang, X. "Overstrength and ductility factors for steel frames designed according to BS 5950", Journal of Structural Engineering, ASCE, 129(8), pp. 1019-1035 (2003).

26. Newmark, N.M. and Hall, W.J. "Seismic design criteria for nuclear reactor facilities", Rep. No. 46, Building Practices for Disaster Mitigation, National Bureau of Standards, U.S. Department of Commerce (1973).

27. Newmark, N.M. and Hall, W.J. "EERI monograph series", Earthquake Spectra and Design, Earthquake Engineering Research Institute, Oakland, California (1982).

28. Miranda, E. "Site-dependent strength reduction factors", Journal of Structural Engineering, ASCE, 119(12), pp. 3503-3519 (1993).

29. Miranda, E., and Bertero, V.V. "Evaluation of strength reduction factors for earthquake-resistant design", Earthquake Spectra, 10(2) pp. 357-379 (1994).

30. Pinho, R. "Shaking table testing of RC walls", ISET Journal of Earthquake Engineering, 37(4), pp. 119-142 (2000).

31. Fagà, E., Rassati, G.A. and Nascimbene, R. "Seismic design of elevated steel tanks with concentrically braced supporting frames", Structures Congress 2012 Proceedings of the 2012 Structures Congress, pp. 14731484 (2012).
32. Wijesundara, K.K., Rassati, G.A., Nascimbene, R. and Bolognini, D. "Seismic performance of brace-beamcolumn connections in concentrically braced frames", Structures Congress, pp. 930-942 (2010).

33. Mpampatsikos, V., Nascimbene, R. and Petrini, L. "A critical review of the R.C. frame existing building assessment procedure according to EUROCODE 8 and Italian Seismic Code", Journal of Earthquake Engineering, 12(S1), pp. 52-82 (2008).

34. Brunesi, E. and Nascimbene, R. "Extreme response of reinforced concrete buildings through fiber force-based finite element analysis", Engineering Structures, 69, pp. 206-215 (2014).

35. Brunesi, E., Nascimbene, R. and Rassati, G.A. "Response of partially-restrained bolted beam-to-column connections under cyclic loads", Journal of Constructional Steel Research, 97, pp. 24-38 (2014).

36. Brunesi, E., Nascimbene, R. and Rassati, G.A. "Seismic response of MRFs with partially-restrained bolted beam-to-column connections through FE analyses", Journal of Constructional Steel Research, 107, pp. 3749 (2015).

\section{Biographies}

Abazar Asghari received his BS degree in Civil Engineering from Isfahan University of Technology, Isfahan, Iran. Also, he received his MS and PhD degrees in Structural Engineering from School of Civil Engineering, College of Engineering, University of Tehran, Tehran, Iran. He is a Faculty Member of the Department of Civil Engineering, Urmia University of Technology, Urmia, Iran. Dr. Asghari's research interests include seismic design of steel structures, error measure and mesh refinement in the finite element analysis, and dynamic of structures.

Behnam Azimi born in 1985, Tabriz, Iran, received his BS degree in Civil Engineering from Azarbijan Shahid Madani University, 2010, Tabriz, Iran. Mr. Azimi has finished his master studies in Structural Engineering in Urmia University of Technology, Urmia, Iran (2013), and he works as a structural designer. 